DOI: $10.15593 / 2224-9877 / 2018.1 .02$

УДК 669: 669-1

\author{
А.В. Гурских \\ АО «ПОЛЕМА», Тула, Россия

\section{ПОВЕДЕНИЕ СПЕЧЕННОЙ АЛЮМИНИЕВОЙ БРОНЗЫ ПРИ ОБРАБОТКЕ ДАВЛЕНИЕМ}

\begin{abstract}
Спеченные материалы демонстрируют некоторое снижение механических свойств из-за остаточной пористости. Для устранения дефектов, возникающих при спекании, применяют операцию доуплотнения, совмещенную с формообразованием. В силу того, что усилия прессования ограничены, плотность прессуемого образца повышается только за счет уменьшения его площади, с возрастанием нагрузки на инструмент, или за счет нагрева заготовки до температуры, заметно снижающей прочность прессуемого материала. При этом возможно окисление материала в открытых порах. После схлопывания пор дальнейшая деформация материала невозможна, а величины испытанной деформации может оказаться недостаточно для существенной проработки структуры во всем объеме спеченного материала.

При свободной осадке образцов величина наложенной деформации ограничивается только мощностью прессового инструмента, поскольку в ходе осадки образцов происходит увеличение площади их сечения, а также деформационное упрочнение материала. Течение материала осуществляется сдвигом вдоль плоскостей максимальных сдвигающих напряжений.

Исследовано влияние температуры на поведение при сжатии спеченной бронзы однофазного Cu-15 ат. \% Al и двухфазного Cu-24 ат. \% Al составов. Установлено, что осадка образцов из спеченных сплавов без разрушения может достигать $30 \%$. Повышение температуры прессования приводит к значительному снижению рабочего давления, однако заметное уплотнение материала наблюдается только при температуре выше $500{ }^{\circ} \mathrm{C}$, когда деформация начинает распределяться по объему образцов относительно однородно.

Показано, что в ходе высокотемпературной осадки происходит разрушение исходной структуры спеченной бронзы путем измельчения, что способствует увеличению прочности материала.

Ключевые слова: спекание, ковка, алюминий, медь, плотность, поры, горячее прессование, интенсивная деформация, алюминиевая бронза, спеченные сплавы.
\end{abstract}

\author{
A.V. Gurskikh \\ JSC "Polema", Tula, Russian Federation
}

\title{
BEHAVIOR OF SINTERED ALUMINUM BRONZE IN PRESSURE PROCESSING
}

Sintered materials exhibit some reduction in mechanical properties due to residual porosity. To eliminate the defects that arise during sintering, a pre-compacting operation combined with shaping is applied. Because the pressing force is limited, it is possible to increase the density of the compacted sample only by decreasing its area, increasing the load on the tool, or by heating the workpiece to a temperature markedly decreasing the strength of the pressed material. It is possible to oxidize the material in open pores. After the collapse of the pores, further deformation of the material is not possible, and the values of the tested material may not be sufficient for a substantial study of the structure in the entire volume of the sintered material.

When the samples are free of sediment, the amount of superimposed deformation is limited only by the power of the press tool, because during the sedimentation of the samples, the area of their cross sections increases, and the deformation hardening of the material. The material flow is carried out by shifting along the planes of the maximum shearing stresses. In the course of the work, the influence of temperature on the behavior of single-phase CU-15 at.\% AL and two-phase CU-24 at.\% AL compositions on the behavior of a special bronze was studied. It was established that the sediment of samples from sintered alloys without destruction can reach $30 \%$. The increase in the pressing temperature leads to a significant decrease in the working pressure, but a noticeable compaction of the material is observed only at a temperature above $500{ }^{\circ} \mathrm{C}$, when the deformation begins to be distributed uniformly over the volume of the samples.

Keywords: sintering, forging, aluminum, copper, density, pores, hot pressing, intensive deformation, aluminum bronze, sintered alloys.

\section{Введение}

Для спеченных материалов характерно наличие остаточной пористости и неоднородное распределение легирующих компонентов [1], что обусловливает снижение их механических свойств. Для устранения указанных дефектов спеченные изделия подвер- 
гают доуплотнению, совмещая его с формообразованием. В ходе такой обработки происходит модификация исходной структуры, степень которой зависит не только от величины наложенной деформации, но и от однородности ее распределения по объему образца, зависящей во многом от применяемой механической схемы деформации [2].

Например, при доуплотнении спеченных образцов в закрытых штампах изменение их поперечного сечения ограничено стенками пресс-формы и процесс протекает при высоком гидростатическом давлении. Полностью устранить поры в массивных образцах таким методом нельзя, поскольку по мере уплотнения материала для заковки оставшихся пор требуется все большее гидростатическое давление [3]: $\eta=$ $=\exp -(\sqrt{3} / c)(p / \tau)$. Здесь $\eta-$ текущая пористость образца, $p$ - гидростатическое давление на поверхности пор, $\tau$ - максимальное напряжение сдвига материала, а $c$ - коэффициент формы пор, равный 0,33 для цилиндрических и 0,25 для сферических пор. Ввиду ограниченности усилия прессования повысить плотность прессуемого образца можно только за счет уменьшения его площади (при этом возрастет нагрузка на инструмент) или за счет нагрева заготовки до температуры, заметно снижающей прочность прессуемого материала [4]. При этом нужны специальные меры по предотвращению окисления материала в открытых порах. После схлопывания пор дальнейшая деформация материала невозможна, а величины испытанной деформации может оказаться недостаточно для существенной проработки структуры во всем объеме спеченного материала [5].

При свободной осадке образцов величина наложенной деформации ограничивается только мощностью прессового инструмента, поскольку в ходе осадки образцов происходит увеличение площади их сечения, а также деформационное упрочнение материала [6]. Течение материала осуществляется сдвигом вдоль плоскостей максимальных сдвигающих напряжений [7]. Если обрабатываемый материал пористый, то указанные плоскости проходят в том числе и через поры. Половинки пор смещаются, площадь их поверхности увеличивается, и берега пор начинают сближаться под действием гидростатического давления, величина которого определяется напряжением течения деформируемого материала. По мере сплющивания и вытягивания поры постепенно превращаются в трещины Гриффитса, устойчивость которых определяется уровнем растягивающих напряжений на концах трещин. Растрескивание материала вследствие самопроизвольного роста указанных дефектов определяет величину допустимой деформации спеченных образцов. Поскольку положение плоскостей максимальных сдвигающих напряжений при монотонных видах деформирования, к которым относится и свободная осадка, не меняется, то поры могут достаточно быстро принять опасные форму и размер, особенно если при этом пластическое течение материала склонно к локализации [8].

Целями настоящей работы являются: изучение влияния температуры прессования на предельную величину деформации, не вызывающую растрескивание образцов в процессе их одноосной осадки, а также изучение особенностей эволюции поровой и зеренной структуры спеченных бронзовых одно- и двухфазных сплавов при такой обработке.

\section{Материалы и методика эксперимента}

В качестве материала для исследований использовались спеченные при $950{ }^{\circ} \mathrm{C}$ прессовки цилиндрической формы, полученные из смесей порошков меди марки ПМС-1 и алюминия марки ПА-4, взятых в соотношении, которое соответствует $\alpha$-твердому 
раствору алюминия в меди (15 ат. \% $\mathrm{Al}$ - сплав 1$)$, а также выходит за область твердого раствора (24 ат. \% Al - сплав 2) - рис. $1[9,10]$. Пористость спеченных образцов составляла 20-25\%. Одноосное сжатие образцов для определения предельно допустимых значений деформации осуществляли на установке МC-500 при комнатной температуре или после предварительного подогрева пресс-формы вместе с образцами в печи СНОЛ до $250-600{ }^{\circ} \mathrm{C}$.

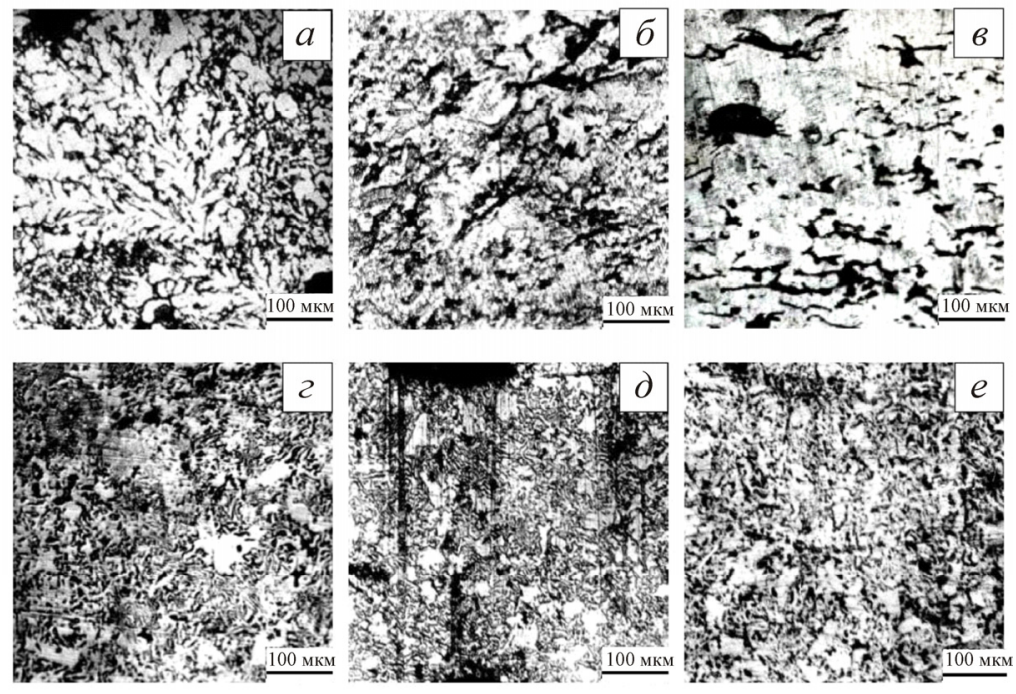

Рис. 1. Микроструктура порошковых сплавов: $a$ - сплав 1 в исходном состоянии; $\sigma$ - после деформирования при $20{ }^{\circ} \mathrm{C} ; в-$ при $600{ }^{\circ} \mathrm{C}$; 2 - сплав 2 в исходном состоянии; $\partial$ - после деформирования при $20^{\circ} \mathrm{C} ; e-$ при $600{ }^{\circ} \mathrm{C}$

Шлифы для металлографических исследований микроструктуры образцов готовили по обычной методике. При анализе структуры особое внимание уделяли характеру эволюции пор, изменению их размеров и формы. Для описания формы пор использовали параметр $K=d_{\min } / d_{\max }$ как соотношение их минимального диаметра к максимальному [11]. На основе полученных статистических данных строили гистограмму, позволяющую определить удельную долю пор определенной формы в исследуемом материале.

Дополнительно измеряли микротвердость деформированных образцов с помощью прибора ПМТ-3 при нагрузке на индентор 20 г и выдержке 10 с.

\section{Результаты и их обсуждение}

В спеченном состоянии сплав 1 представляет собой однофазный материал на основе $\alpha$-твердого раствора алюминия в меди с выраженной дендритной структурой, средний размер зерен которой составляет 30-60 мкм (рис. 1, a). Другим элементом структуры спеченной бронзы были поры, с преобладанием узких вытянутых пор, расположенных в междендритных промежутках, и крупных округлых пор со средним диаметром 30-50 мкм, образовавшихся на месте растворившихся частиц алюминия в меди. Такая структура типична для спеченных сплавов с односторонней растворимостью легирующего элемента [12]. Микротвердость спеченного сплава в среднем составляла $700 \pm 35$ МПа. 
Основу структуры сплава 2 после спекания составляют чередующиеся со средней толщиной 2-3 мкм пластины $\alpha-$ и $\gamma$-фаз, в которые включены крупные округлой формы зерна $\alpha$-фазы. Объемная доля $\gamma$-фазы составляла примерно $42 \%$, что согласуется с диаграммой фазового равновесия системы $\mathrm{Cu}-\mathrm{Al}$ [13]. Микротвердость эвтектоидных областей составляла $2173 \pm 50$ МПа, а заключенных в них зерен твердого раствора $\alpha$-фазы $1175 \pm 20$ МПа.

Поры в спеченных сплавах 1 и 2 имеют бимодальное распределение по форме и размерам. Средний диаметр крупных округлых пор, образовавшихся на месте растворившихся частиц алюминия в меди [14], в сплаве 1 составил 30-50 мкм, а в двухфазном сплаве 2 - 50-60 мкм. Мелкие и вытянутые поры располагались либо в междендритном пространстве в сплаве 1, либо в двухфазных областях в случае сплава 2 (см. рис. 1, $a$, 2) и при определении $K$ не учитывались.

Суммарная величина осадки образцов из сплава 1 составляла примерно $30 \%$. В результате их плотность заметно повышалась, однако характер уплотнения и особенности эволюции поровой структуры материала существенно зависели от температуры прессования [15]. О характере ее протекания и распределении деформации по объему образца можно судить по изменению формы кривой распределения параметра $K$ (рис. 2), которая в спеченном материале есть кривая с выраженным максимумом вблизи больших его значений. Например, если при осадке образца деформация распределяется по объему равномерно, то максимум будет смещаться в сторону меньших $K$, но форма кривой распределения останется примерно такой же, что и до прессования. При неоднородном течении материала максимум будет размываться и снижаться за счет появления малых значений $K[16]$.
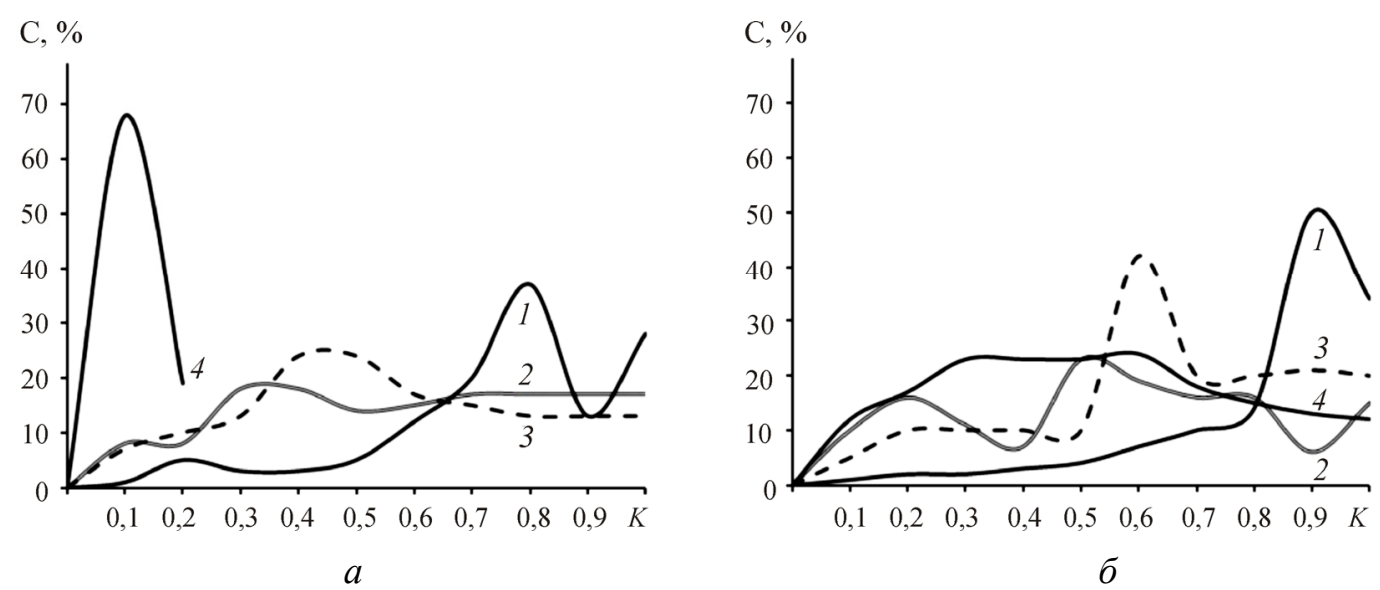

Рис. 2. Распределение пор по конфигурации $\left(K=d_{\min } / d_{\max }\right): a-$ в сплаве $1 ; \sigma-$ в сплаве 2 ; 1 - в исходном состоянии; 2-4 - после осадки при 20,370 и $600{ }^{\circ} \mathrm{C}$ соответственно

Так, из рис. 2, $a$ видно, что усадка образцов при значениях температуры 20 и $370{ }^{\circ} \mathrm{C}$ протекает однородно не по всему объему образцов, особенно в первом случае, поскольку по окончании прессования остается значительная часть крупных округлых исходных пор. Напротив, при осадке при $600{ }^{\circ} \mathrm{C}$ таких пор практически не остается, кривая 4 распределения параметра $K$ имеет острый максимум в районе сильно сплющенных пор. Из рис. 1 видно, что такие поры имеют не только сплющенную форму, как после осадки при более низкой температуре (рис. 1, б), но и мелкий размер, поскольку многие из 
них оказались пережатыми, а стенки пор в местах пережима срослись (рис. 1, в). Исходная дендритная структура сплава 1 в процессе сжатия была разрушена (см. рис. 1) независимо от температуры прессования.

Изменения структуры пор при сжатии двухфазного сплава 2 имеют примерно такой же характер, как и в предыдущем случае (см. рис. 1 и 2). После осадки на 30 \% в материале остается заметная доля (около $10 \%$ ) исходных округлых пор. При этом поры с $K<0,2$ появляются только при высокотемпературной осадке. Иными словами, при осадке образцов распределение деформации по их объему остается относительно неоднородным, поэтому пик кривой $K$ не только смещается к большим значениям параметpa, но и снижается. Кривая распределения $K$ становится более пологой.

Из проведенного анализа кривых распределения $K$ следует, что материал в окрестностях пор упрочнен сильнее, чем на большом расстоянии от них [17]. Происходит это по той причине, что вокруг исходных частиц алюминия быстро образуется интерметаллический слой меди, насыщенный атомами алюминия, который тормозит растекание эвтектической жидкости по объему прессовки. За время существования интерметаллидного барьерного слоя прилегающие к нему слои меди успевают сильнее насытиться атомами алюминия, чем стоящие более далеко медные частицы, к которым алюминий подводится только после расплавления интерметаллидного слоя. Особенно заметен этот эффект в случае сплава 1. Однако при нагреве прессовки до $600{ }^{\circ} \mathrm{C}$ механическая прочность $\alpha$-фазы сильно снижается, эффект от твердорастворного упрочнения нивелируется и все поры сильно сжимаются (см. рис. 2, a, кривая 4).

В случае сплава 2 поры окружены слоем двухфазного материала, который менее подвержен высокотемпературному разупрочнению. Таким образом, форма пор при ковке образцов подвергается меньшему изменению, и доля их с малыми значениями $K$ незначительна. Пластическое течение по мере деформационного упрочнения материала начинает локализоваться в более мягких областях. Это видно по структуре сплава на рис. 1, где целые области, не охваченные пластическим течением, сохраняют свою исходную структуру с чередующимися пластинами $\alpha$ - и $\gamma$-фаз. Только нагрев сплава 2 до $600{ }^{\circ} \mathrm{C}$, когда выделения второй фазы трансформируются из твердой $\gamma$-фазы в более пластичную $\beta$-фазу [4], приводит к вовлечению в пластическое течение областей вокруг пор, что незамедлительно сказывается на появлении последних с малым значением $K$ (см. рис. 2, кривая 4), и к полному разрушению пластинчатых выделений на мелкие дисперсные частицы (рис. $1, e$ ).

О существенном разупрочнении сплава 2 из-за распада $\gamma$-фазы при $600{ }^{\circ} \mathrm{C}$ свидетельствует и соответствующая кривая течения 5 на рис. 3. Прочность сплава при деформации образцов почти до $25 \%$ практически не растет, только после деформационной проработки всего материала начинает медленно увеличиваться.

В случае более низкой температуры осадки, когда частицы второй фазы сохраняются в своей твердой и хрупкой $\gamma$-модификации, их влияние на скорость упрочнения материала при прессовании незначительное. Кривые течения 1-4 на рис. 3 у обоих сплавов имеют практически равный наклон. Видимо, при развитии деформации вдоль линий максимального сдвигового напряжения пластинчатые выделения хрупкой фазы легко разрушаются и не оказывают значительного сопротивления. При низких значениях температуры прессования таких разрушений множество, микротрещины становятся источниками критических разрушающих напряжений и, сливаясь, быстро подрастают 
до критических размеров. Таким образом, предельная степень осадки образцов двухфазного сплава 2 оказывается ограниченной, ее величина не дотягивает до $30 \%$ (рис. 3, б, кривые 1 и 2).
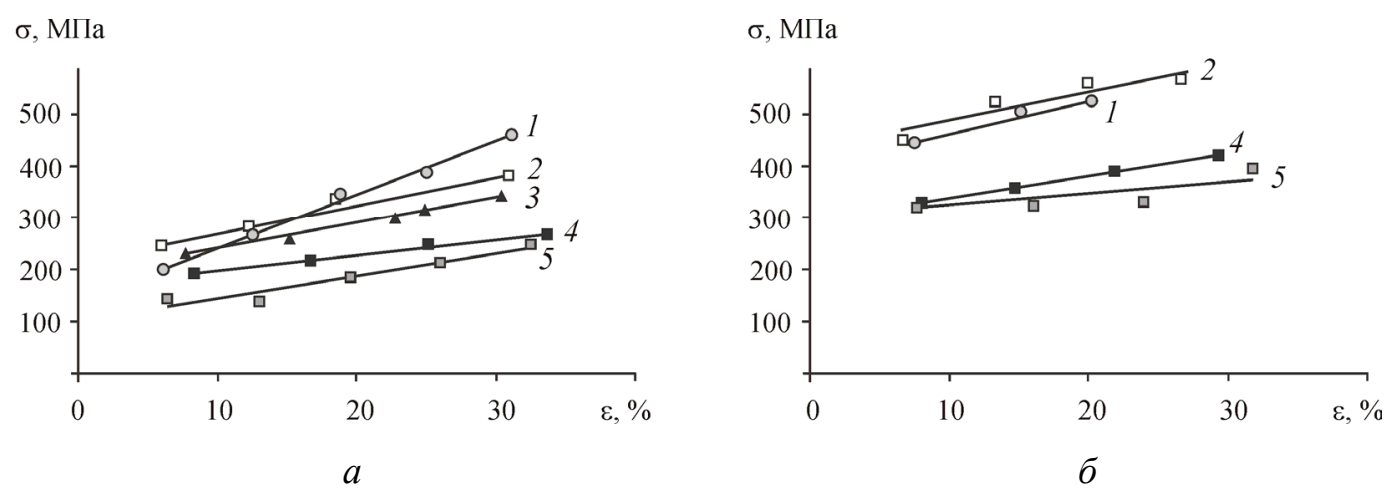

Рис. 3. Кривые «напряжения - деформация»: $a$ - для состава $1 ; \sigma$ - для состава $2 ; 1$ - при температуре деформирования $20{ }^{\circ} \mathrm{C} ; 2-250{ }^{\circ} \mathrm{C} ; 3-370{ }^{\circ} \mathrm{C} ; 4-500{ }^{\circ} \mathrm{C} ; 5-600{ }^{\circ} \mathrm{C}$

Напряжение течения образцов сплава 2 композиционного состава определяется объемной долей твердой и мягкой фаз, т.е. по закону механической смеси. Однако с началом пластического течения включения $\gamma$-фазы разрушаются и влияния на темпы деформационного упрочнения материала практически не оказывают. Деформационное упрочнение спеченных бронз обеспечивается упрочнением пластичной $\alpha$-фазы. На это указывает тот факт, что наклон кривых течения сплавов 1 и 2 фактически совпадает (см. рис. $3, a, \sigma)$, т.е. при осадке бронзовых образцов действует один и тот же механизм деформационного упрочнения материала, независимо от наличия в нем частиц хрупкой $\gamma$-фазы.

В то же время наклон деформационной кривой сплава 1 при холодном прессовании несколько выше, чем у остальных кривых (см. рис. 3, $a$, кривая 1), т.е. упрочнение материала происходило более быстрыми темпами. Специальных исследований для объяснения этого факта не проводилось, но можно предположить, что по причине неравномерного распределения алюминия по объему спеченного материала в некоторых его областях сопротивление движению дислокаций выше, например из-за образования тормозящих скоплений по типу облаков Сузуки. С повышением температуры прессования и увеличением подвижности атомов алюминия дислокации от них отрываются более легко или таких облаков вовсе не образуется из-за быстрого выравнивания концентрации элементов.

Как следует из рис. 3, поровая структура спеченных сплавов также оказывает незначительное влияние на скорость упрочнения, хотя согласно данным таблицы ее количественные характеристики существенно отличаются от состава спеченной бронзы и температуры ее обработки [18]. В то же время, как видно из таблицы, величина конечной пористости деформированных образцов $\left(\Pi_{\kappa}\right)$ оказывает существенное влияние на микротвердость сплавов $H_{\mu}$. В общем случае $H_{\mu}$ тем выше, чем выше оказывается плотность материала после осадки, особенно это влияние заметно для образцов сплава 1. При этом степень деформационного упрочнения бронзовых образцов оказывает на величину микротвердости значительно более слабое влияние, чем плотность, и в результате $H_{\mu}$ оказывается меньше у образцов, напряжение течения которых при прессовании было выше. 
Влияние температуры деформирования на остаточную пористость $\left(\Pi_{\kappa}\right)$ и микротвердость $\left(H_{\mu}\right)$ спеченного порошкового сплава $\mathrm{Cu}-15$ ат. \% $\mathrm{Al}(1)$ и $\mathrm{Cu}-24$ ат. \% $\mathrm{Al}(2)$

\begin{tabular}{|c|c|c|c|}
\hline Состав & $T_{\text {деф }},{ }^{\circ} \mathrm{C}$ & $\Pi_{\kappa}, \%$ & $H_{\mu}, \mathrm{M}$ Па \\
\hline \multirow{4}{*}{1} & 20 & $5,9 \pm 2,0$ & $1300 \pm 50$ \\
\cline { 2 - 4 } & 250 & $9,0 \pm 1,5$ & $1233 \pm 61$ \\
\cline { 2 - 4 } & 370 & $11,9 \pm 3,0$ & $994 \pm 25$ \\
\cline { 2 - 4 } & 500 & $5,2 \pm 1,7$ & $1452 \pm 37$ \\
\cline { 2 - 4 } & 600 & $3,5 \pm 0,6$ & $1468 \pm 70$ \\
\hline \multirow{4}{*}{2} & 20 & $17,2 \pm 4,0$ & $1359 \pm 41$ \\
\cline { 2 - 4 } & 250 & $11,4 \pm 2,0$ & $2020 \pm 72$ \\
\cline { 2 - 4 } & 370 & $14,4 \pm 1,4$ & $1223 \pm 43$ \\
\cline { 2 - 4 } & 500 & $3,7 \pm 0,3$ & $1833 \pm 27$ \\
\cline { 2 - 4 } & 600 & $6,9 \pm 2,6$ & $2452 \pm 67$ \\
\hline
\end{tabular}

Данные таблицы позволяют также сделать интересное заключение относительно характера пластического течения материала сплавов при прессовании. Так, при примерно равной величине осадки пористость образцов оказывается тем выше, чем ниже была температура их прессования. Это указывает на то, что сильное упрочнение и высокий предел текучести спеченной бронзы не способствуют однородному распределению деформации по объему осаживаемых образцов [19]. Повышенная концентрация алюминия и высокое напряжение течения материала вблизи больших исходных пор приводят к тому, что данные области не вовлекаются в пластическое течение образцов, а заключенные в них поры мало меняют свою конфигурацию. И только нагрев сплавов до $500{ }^{\circ} \mathrm{C}$ и выше способствует разупрочнению таких областей и вовлечению их в пластическое течение. В результате деформация исходных пор становится пропорциональной величине деформации всего образца.

\section{Заключение}

Таким образом, из представленных результатов следует, что осадку спеченных бронзовых образцов с целью их уплотнения и модификации структуры следует проводить при температуре не ниже $500{ }^{\circ} \mathrm{C}$. Однако ввиду возможного интенсивного окисления при нагреве спеченных пористых образцов из алюминиевой бронзы их пластическую обработку следует начинать при пониженных значениях температуры до исчезновения открытой пористости, и только затем температура прессования может быть повышена.

В ходе высокотемпературной осадки происходит разрушение исходной дендритной или эвтектоидной структуры спеченной бронзы, она измельчается, что способствует увеличению прочности материала. Кроме того, при высокой температуре прессования пластическое течение принимает однородный характер, что способствует исчезновению крупных остаточных пор и уплотнению бронзовых образцов, повышению их микротвердости. Таким образом, появляется возможность применения спеченной бронзы в нагруженных узлах трения, где прежде преимущественно использовались литые бронзы [20].

Работа выполнена при финансовой поддержке гранта РФФИ №16-38-00200 мол_a. 


\section{Список литературы}

1. Федорченко И.М., Андриевский Р.А. Основы порошковой металлургии. - Киев: Изд-во Акад. наук УССР, 1963. - 420 с.

2. Процессы пластического структурообразования металлов / В.М. Сегал, В.И. Резников, В.И. Копылов [и др.]. - Минск: Навука і тэхніка, 1994. - 232 с.

3. Сегал В.М., Резников В.И., Малышев В.Ф. Измерение плотности пористых материалов при пластическом формоизменении // Порошковая металлургия. - 1979. - № 7. - С. 6.

4. Промышленная технология горячего прессования порошковых изделий / Ю.Г. Дорофеев, Б.Г. Гасанов, В.Ю. Дорофеев [и др.]. - М.: Металлургия, 1990. - 206 с.

5. Рябичева Л.А., Кравцова Ю.В. Влияние условий деформирования на характер течения пористого материала при одноосном сжатии // Сучасні проблеми металургіi: наукові вісті. Т. 5. Пластична деформація металів. - Дніпропетровськ: Системні технологіi, 2002. - С. 133-137.

6. Теория обработки металлов давлением / И.Я. Тарновский [и др.]. - М.: Металлургиздат, 1963. $-672 \mathrm{c}$.

7. Качанов Л.М. Основы теории пластичности. - М.: Наука, 1969. - 420 с.

8. Дорофеев Ю.Г. Динамическое горячее прессование пористых порошковых заготовок. М.: Металлургия, 1977. - 216 с.

9. Осинцев О.Е., Федоров В.Н. Медь и медные сплавы. - М.: Машиностроение, 2004. - 336 с.

10. Савицкий А.П. Жидкофазное спекание систем с взаимодействующими компонентами. - Новосибирск: Наука, 1991. - 183 с.

11. Салтыков С.А. Стереометрическая металлография. - М.: Металлургия, 1970. - 376 с.

12. Korosteleva E.N., Pribytkov G.A., Gurskikh A.V. Bulk changes and struc-turization in solid-phase sintering of titanium-silicon powder mixtures // Powder Metallurgy and Metal Ceramics. - 2009. - Vol. 48, № 1-2. - Р. 8-12.

13. Диаграммы состояния двойных металлических систем / под общ. ред. Н.П. Лякишева. М.: Машиностроение, 1996. - Т. 1. - 996 с.

14. Коростелева Е.Н., Русин Н.М., Гурских А.В. Изменение структуры спеченной алюминиевой бронзы после обработки методом интенсивной пластической деформации // Физическая мезомеханика. Спец. выпуск. - 2004. - Т. 7. - С. 73-74.

15. Rusin N.M., Skorentsev A.L., Mishin I.P. Evolution of structure and properties of Al-Sn composites under deformation // Journal Perspektivnye Materially. - 2015. - Vol. 6. - P. 5-17.

16. Noskova N.I., Korshunov A.G., Korznikov A.V. Microstructure and tribological properties of Al-Sn, $\mathrm{Al}-\mathrm{Sn}-\mathrm{Pb}$, and $\mathrm{Sn}-\mathrm{Sb}-\mathrm{Cu}$ alloys subjected to severe plastic deformation // Metal Science and Heat Treatment. 2008. - Vol. 50, № 11-12. - P. 593-599.

17. Арефьев Б.А., Кулешов В.В., Пановко В.М. Закономерности соединения порошковых частиц при пластической деформации // Порошковая металлургия. - 1990. - № 8. - С. 15-20.

18. Дидикин Г.Г., Гречанюк Н.И., Мочван Б.А. Прочность и пластичность двухфазных конденсированных материалов $\mathrm{Mo}-\mathrm{Cu}, \mathrm{Cr}-\mathrm{Cu}, \mathrm{Fe}-\mathrm{Cu} / /$ Проблемы специальной электрометаллургии. - 1990. № 4. - C. 51-55.

19. Дорофеев Ю.Г., Сергиенко С.Н. Оценка степени неравномерности уплотнения при поперечной горячей штамповке // Порошковая металлургия. - 1995. - № 3/4. - С. 20-23.

20. Русин Н.М., Скоренцев А.Л., Коростелева Е.Н. Исследование влияния структуры на триботехнические свойства самосмазывающихся материалов на примере композитов Al-Sn // Известия вузов. Физика. - 2013. - Т. 56, № 7/2. - С. 321-327.

\section{References}

1. Fedorchenko I.M., Andrievskii R.A. Osnovy poroshkovoi metallurgii [Fundamentals of powder metallurgy]. Kiev: Izdatel'stvo Akademii nauk Ukrainskoi Sovetskoi Sotsialisticheskoi Respubliki, 1963, 420 p.

2. Segal V.M., Reznikov V.I., Kopylov V.I. et al. Protsessy plasticheskogo strukturoobrazovaniia metallov [Processes of plastic structurization of metals]. Minsk: Navuka i tekhnika, 1994, 232 p.

3. Segal V.M., Reznikov V.I., Malyshev V.F. Izmerenie plotnosti poristykh materialov pri plasticheskom formoizmenenii [Measurement of density of porous materials at plastic forming]. Poroshkovaia metallurgiia, 1979, no. 7, pp. 6 . 
4. Dorofeev Iu.G., Gasanov B.G., Dorofeev V.Iu. Promyshlennaia tekhnologiia goriachego pressovaniia poroshkovykh izdelii [Industrial technology of hot pressing of powder products]. Moscow: Metallurgiia, 1990, $206 \mathrm{p}$.

5. Riabicheva L.A., Kravtsova Iu.V. Vliianie uslovii deformirovaniia na kharakter techeniia poristogo materiala pri odnoosnom szhatii [Influence of conditions of deformation on character of a current of porous material at monoaxial compression]. Suchasni problemi metalurgii: naukovi visti, vol. 5. Plastichna deformatsiia metaliv. Dnipropetrovs'k: Sistemni tekhnologii, 2002, pp. 133-137.

6. Tarnovskii I.Ia. at al. Teoriia obrabotki metallov davleniem [Theory of processing of metals pressure]. Moscow: Metallurgizdat, 1963, 672 p.

7. Kachanov L.M. Osnovy teorii plastichnosti [Bases of the theory of plasticity]. Moscow: Nauka, 1969, $420 \mathrm{p}$.

8. Dorofeev Iu.G. Dinamicheskoe goriachee pressovanie poristykh poroshkovykh zagotovok [Dynamic hot pressing of porous powder preparations]. Moscow: Metallurgiia, 1977, $216 \mathrm{p}$.

9. Osintsev O.E., Fedorov V.N. Med' i mednye splavy [Copper and copper alloys]. Moscow: Mashinostroenie, 2004, $336 \mathrm{p}$.

10. Savitskii A.P. Zhidkofaznoe spekanie sistem s vzaimodeistvuiushchimi komponentami [Liquid-phase agglomeration of systems with the interacting components]. Novosibirsk: Nauka, 1991, 183 p.

11. Saltykov S.A. Stereometricheskaia metallografiia. - M.: Metallurgiia, 1970. - $376 \mathrm{~s}$.

12. Korosteleva E.N., Pribytkov G.A., Gurskikh A.V. Bulk changes and structurization in solid-phase sintering of titanium-silicon powder mixtures // Powder Metallurgy and Metal Ceramics. - 2009. - Vol. 48,

№ 1-2. - P. 8-12.

13. Diagrammy sostoianiia dvoinykh metallicheskikh sistem [Charts of a condition of double metal systems]. Ed. N.P. Liakisheva. Moscow: Mashinostroenie, 1996, vol. 1, 996 p.

14. Korosteleva E.N., Rusin N.M., Gurskikh A.V. Izmenenie struktury spechennoi aliuminievoi bronzy posle obrabotki metodom intensivnoi plasticheskoi deformatsii [Change of structure of the baked aluminum bronze after processing by method of intensive plastic deformation]. Fizicheskaia mezomekhanika. Spetsial'nyi vypusk, 2004, vol. 7, pp. 73-74.

15. Rusin N.M., Skorentsev A.L., Mishin I.P. Evolution of structure and properties of Al-Sn composites under deformation. Journal Perspektivnye Materially, 2015, vol. 6, pp. 5-17.

16. Noskova N.I., Korshunov A.G., Korznikov A.V. Microstructure and tribological properties of Al-Sn, $\mathrm{Al}-\mathrm{Sn}-\mathrm{Pb}$, and $\mathrm{Sn}-\mathrm{Sb}-\mathrm{Cu}$ alloys subjected to severe plastic deformation. Metal Science and Heat Treatment, 2008, vol. 50, no. 11-12, pp. 593-599.

17. Aref'ev B.A., Kuleshov V.V., Panovko V.M. Zakonomernosti soedineniia poroshkovykh chastits pri plasticheskoi deformatsii [Regularities of connection of powder particles at plastic deformation]. Poroshkovaia metallurgiia, 1990, no. 8, pp. 15-20.

18. Didikin G.G., Grechaniuk N.I., Mochvan B.A. Prochnost' i plastichnost' dvukhfaznykh kondensirovannykh materialov $\mathrm{Mo}-\mathrm{Cu}, \mathrm{Cr}-\mathrm{Cu}, \mathrm{Fe}-\mathrm{Cu}$ [Durability and plasticity of the two-phase condensed materials $\mathrm{Mo}-\mathrm{Cu}, \mathrm{Cr}-\mathrm{Cu}, \mathrm{Fe}-\mathrm{Cu}$ ]. Problemy spetsial'noi elektrometallurgii, 1990, no. 4, pp. 51-55.

19. Dorofeev Iu.G., Sergienko S.N. Otsenka stepeni neravnomernosti uplotneniia pri poperechnoi goriachei shtampovke [Assessment of degree of unevenness of consolidation at cross hot stamping]. Poroshkovaia metallurgiia, 1995, no. 3/4, pp. 20-23.

20. Rusin N.M., Skorentsev A.L., Korosteleva E.N. Issledovanie vliianiia struktury na tribotekhnicheskie svoistva samosmazyvaiushchikhsia materialov na primere kompozitov Al-Sn [Research of influence of structure on tribotechnical properties of the self-greased materials on the example of Al-Sn composites]. Izvestiia vuzov. Fizika, 2013, vol. 56, no. 7/2, pp. 321-327.

Получено 12.12.2017

\section{Об авторе}

Гурских Алексей Валерьевич (Тула, Россия) - кандидат технических наук, начальник исследовательской лаборатории АО «ПОЛЕМА»; e-mail: avg@polema.net.

\section{About the author}

Aleksei V. Gurskikh (Tula, Russian Federation) - Ph. D. in Technical Sciences, Head, Reseaech Laboratory JSC "Polema"; e-mail: avg@polema.net. 